\title{
PHILOSOPHY AS A CULTURAL RESOURCE AND MEDIUM OF REFLECTION FOR HERMANN WEYL
}

\author{
Erhard ScHOLZ
}

\begin{abstract}
RÉSUMÉ : Dans un discours prononcé à Zurich vers la fin des années 1940, Hermann Weyl a examiné l'épistémologie dialectique de Ferdinand Gonseth et l'a considérée comme trop strictement limitée aux aspects de changement historique. Son expérience de la philosophie diaclectique post-kantienne, en particulier la dérivation du concept de l'espace et de la matière chez Johann Gottlieb Fichte, avait constitué une base dialectique solide pour ses propres études de 1918 en une géométrie purement infinitésimale et la théorie antérieure d'un champ de matière géométriquement unifié (en prolongement du programme Mie-Hilbert). Bien que Weyl se fût alors éloigné des aspects spéculatifs de la philosophie de sa jeunesse et eût montré, en particulier, moins d'enthousiasme qu'auparavant pour Fichte, il nourrissait encore de nombreux doutes sur la base culturelle de la science mathématique moderne et sur son rôle dans la culture matérielle du modernisme de pointe. Pour Weyl, la « réflexion » philosophique était une nécessité culturelle ; il se tourna alors vers l'existentialisme de Karl Jaspers et de Martin Heidegger pour trouver des raisons plus profondes, dans un mouvement comparable à son orientation vers la philosophie de Fichte après la Première Guerre mondiale. Le débat de la fin des années 1940 peut être compris comme une sorte de supplément postérieur à la Seconde Guerre mondiale par rapport à ses commentaires plus connus sur les mathématiques et les sciences naturelles publiés au milieu des années 1920.
\end{abstract}

MoTS-CLÉs : Weyl, Gonseth, Fichte, Heidegger, notion d'espace.

ABSTRACT : In a talk given at Zurich in the late 1940s, Hermann Weyl discussed Ferdinand Gonseth's dialectical epistemology and considered it as being restricted too strictly to aspects of historical change. His experiences with post-Kantian dialectical philosophy, in particular Johann Gottlieb Fichte's derivation of the concept of space and matter, had been a stronger dialectical background for his own 1918 studies in purely infinitesimal geometry and the early geometrically unified field theory of matter (extending the Mie-Hilbert program). Although now Weyl distantiated himself from the speculative features of his youthful philosophizing and in particular from his earlier enthusiasm for Fichte, he again had deep doubts as to the cultural foundations of modern mathematical sciences and its role in material culture of high modernity. For Weyl, philosophical « reflection » was a cultural necessity ; he now turned towards Karl Jaspers' and Martin Heidegger's existentialism to find deeper grounds, similar to his turn towards Fichte's philosophy after World War I. The discussion in the late 1940s can be read as a kind of post-World-War-II "Nachtrag » to Weyl's more widely known philosophical comments on mathematics and the natural sciences published in the middle of the 1920s.

KEYWORDS : Weyl, Gonseth, Fichte, Heidegger, concept of space.

Revue de synthèse : 5érie, année 2005/2, p. 331-351. 
ZuSAMmENFASSUNG : In einem Vortrag in den späten 1940er Jahren diskutierte Hermann Weyl die dialektische Epistemologie Ferdinand Gonseths als eine Auffassung, die primär auf die Aspekte historischen Wandels von Wissenssystemen ausgerichtet sei. Seine eigenen, mittlerweile schon etwa 30 Jahre zurück liegenden Erfahrungen mit der nach-kantischen dialektischen Philosophie entsprangen einer Lektüre von Johann Gottlieb Fichtes Wissenschaftslehre, insbesondere der fichteschen Ableitung der Begriffe von Raum und Materie. Diese Studien bildeten damals einen Hintergrund für Weyls Forschungen zur « reinen Infinitesimalgeometrie » und die von ihm im Jahre 1918 vorgeschlagene erste geometrische einheitliche Feldtheorie der Materie (in Radikalisierung und Ausbau eines von David Hilbert und Gustav Mie gestarteten Programms). Weyl distanzierte sich in den 1940er Jahren von den allzu spekulativen Zügen seiner Jugendphilosophie, insbesondere von seinem damaligen Fichte-Enthusiasmus, der einen zeithistorischen Hintergrund in der Krisenerfahrung des ausgehenden (ersten) Weltkrieges und der Gründungswirren der Weimarer Republik hatte. Drei Jahrzehnte später hatte er jedoch erneut tiefe Zweifel an den kulturellen Grundlagen der modernen mathematischen Naturwissenschaften und ihrer praktischen Rolle in der Hochmoderne. Weyl sah tiefe Risse in lebensweltlicher Erfahrung und Wissenstrukturen der Naturwissenschaften seiner Zeit, die seiner Auffassung nach zu dialektischem Nach-Denken herausforderte. Er selbst bezeichnete das ganz klassisch als «Besinnung ». Bezugspunkte dieser kulturell notwendigen Besinnung stellten für Weyl nun die Philosophien Karl Jaspers und Martin Heideggers dar. In deren Existenzialphilosophie hoffte er tieferen Grund zu finden, ähnlich wie er in der Krisenerfahrung nach dem ersten Weltkrieg bei Fichte «Rat» gesucht (und zu finden geglaubt) hatte. Weyls Diskussionsbeiträge der späten 1940er Jahre verdienen es, gewissermaßen als Nachtrag zu seinen weithin bekannten Ausführungen zur Philosophie der Mathematik und der Naturwissenschaften der 1920er Jahre, breiter zur Kenntnis genommen zu werden.

STICHWÖRTER : Weyl, Gonseth, Fichte, Heidegger, Raumbegriff.

Ehrard ScHOLZ, born in 1947, is professor of the history of mathematics. His research deals with mathematics, physics and the philosophy of the $\mathrm{XIX}^{\text {th }}$ and $\mathrm{XX}^{\text {th }}$ centuries, Hermann Weyl and Felix Hausdorff.

Address : Universität Wuppertal, Fachbereich C-Mathematik, D-42097 Wuppertal.

E-mail: scholz@math.uni-wuppertal.de 
Philosophers might get interested in Hermann Weyl for many reasons. One of these may be his explicitly philosophical publications, first of all and best known his Philosophie der Mathematik und Naturwissenschaften ${ }^{1}$ written in 1926 as a contribution to the Handbuch der Philosophie. Moreover his mathematical and scientific work contains in many places, sometimes in decisive branching regions of his thought, philosophical arguments from which Weyl drew motivations for the scientific questions posed or the research orientation chosen.

Among philosophies to which Weyl referred, Edmund Husserl's phenomenology is the best known. Weyl's relationship to phenomenology has been investigated and documented in several publications ${ }^{2}$, but Weyl never became a devoted adherent of any single philosophy. He rather was a wanderer through the philosophical fields differing with the changes in his scientific views ${ }^{3}$, his personal environment ${ }^{4}$, and with cultural and social breaks in his environment. In particular he strongly felt the influences of both great wars of the $\mathrm{xx}^{\text {th }}$ century and was deeply affected by the social and cultural changes resulting from them.

On this occasion I do not want to go into either Weyl's more systematic exposition of a Philosophy of mathematics and natural sciences ${ }^{5}$ or his relationship with Husserl's philosophy. Rather I shall discuss some aspects of his relationship with dialectical philosophies of his time, those of Ferdinand Gonseth and Martin Heidegger, or of some identifiable influence on his scientific work, like Johann Gottlieb Fichte's Wissenschaftslehre, which Weyl came close to in his early years at Zurich, under the influence of Fritz Medicus ${ }^{6}$.

1. WEYL, 1927.

2. Among them, see Van Dalen, 1984, Tonietti, 1988, Da Silva, 1997, Tieszen, 2000, Mancosu and RYCKMAN, 2002. Da Silva argues convincingly for a close methodological link between Husserl and Weyl's Das Kontinuum, whereas he is much more cautious on Husserl's overall role for Weyl than Tonietti. I tend to be even more cautious and agree with the sceptical remarks in this respect by Paolo Mancosu and Thomas Ryckman in Mancosu and Ryckman, 2002, at the occasion of their edition of and comments on the correspondence between Hermann Weyl and Oskar Becker. See below, p. 338, at the beginning of the section «Fichte's dialectical construction of the concept of space $»$.

3. An early example was his alienation from a (narrow) Kantianism under the influence of his awareness of Hilbert's work on the foundations of geometry at the beginning of his university studies in $1904 / 1905$.

4. His personal relationship with Husserl's student Helene Joseph, beginning in 1912 and soon to become his wife, and his acquaintance and later friendship with Fritz Medicus, professor of pedagogy and philosophy in Zurich, after 1913 had strong influences on the philosophical world of discourse, in which Weyl chose his own point of view.

5. WeYL, 1949b.

6. For a better evaluation of the character of this « influence », see the discussion in the last section of this paper, p. 346 . 


\section{SOME REMARKS BY WEYL \\ ON GONSETH'S DIALECTICAL PHILOSOPHY AND ON HEIDEGGER}

In his philosophically and foundationally (with respect to mathematics) most radical phase, between 1916 and 1923/1924, Weyl pursued his intention of basing mathematics and physics on «immediate intuition ${ }^{7}$ » (unmittelbare Einsicht) or on what he called an «analysis of essence attempted by phenomenological philosophy ${ }^{8}$ » (von der phänomenologischen Philosophie (Husserl) angestrebte Wesensanalyse). At that time he rejected the more formal methods of construction of mathematical knowledge proposed, among others, by his former teacher David Hilbert. In the middle of the 1920s he reapproached Hilbert's position on the foundations of mathematics to a certain degree and conceded to formal mathematics founded on axiomatic principles a potentiality for the intellectual appropriation of external reality or its symbolic representation, as Weyl preferred to formulate it, which went far beyond what he had accepted some years earlier. In a phase of restructuring of his thought between 1920 and 1922, he came to the conviction that some «transcendent reality » (God, matter...) lies beyond the realm of phenomenologically accessible reality, which at least in some aspects (e.g. matter understood as a dynamic agent) might be indirectly represented by mathematical symbols the nature and exact form of which had still to be explored (for a short phase in the early 1920s he considered singularities of classical fields as a possible candidate) or invented and developed (at the end of the 1920s he turned towards spinor fields with an additional $U(1)$ gauge symmetry and, at least in principle, their mathematically highly problematical second quantization). In this case he realized that formal mathematics might even have an advantage over immediately insightful («phenomenological ») mathematics, because in its conceptual constitution it was free from the restrictions of the latter. I will call this view the symbolic realism of the « mature » Weyl.

The topic of symbolic realism was taken up and elaborated by Weyl in his contribution «Wissenschaft als symbolische Konstruktion des Menschen » (Science as symbolic construction of man) to the Eranos Jahrbuch ${ }^{9}$, in which he sketched, now as a sexagenarian, a kind of résumé of the transition from the early modern, mechanistic image of nature and the role of mathematics in it to the state it had assumed in the classical modern view of the first half of the $\mathrm{Xx}^{\text {th }}$ century. This résumé is comparable to and continues the one he had attempted in his Philosophie der Mathematik und der Naturwissenschaften more than twenty years earlier. It was quite different in content from the first one, due to further advances, not at all reassuring for Weyl, in the foundations of mathematics and in fundamental physics.

Weyl characterized the quintessence of the transition as a replacement of the old « mechanistic construction of the world » in the sense of some assumed spatio-temporal materiality understood in an atomistic sense by a « construction in pure symbols $»{ }^{10}$. He deplored the fact that physicists and philosophers had both continued to

\footnotetext{
7. WEYL, 1921, p. 146.

8. WeYL, 1918b, p. 146.

9. WeYL, 1948.

10. WeYL, 1948, p. 295.
} 
« stick stubbornly to the principles of a mechanistic interpretation of the world (mechanistische Weltdeutung) after physics had, in its factual structure, already outgrown the latter. They have the same excuse as the inhabitant of the mainland (Landmensch) who for the first time travels on the open sea : he will desperately try to stay in sight of the vanishing coast line, as long as there is no other coast in sight, towards which he steers ${ }^{11} »$.

In his own perspective of a «construction of the world in pure symbols », his symbolic realism as I called it above, Weyl hoped to see the first contours of a «new coast line ». He frankly admitted, however, that he was not able to exclude the possibility that, perhaps, «we are only deceived by a fog-bank » ${ }^{12}$. On that background he discussed Einstein's principle of relativity (approvingly) and Bohr's principle of complementarity, which he wanted to accept only as far as it «corresponds to a fact in quantum physics, which can be given a precise mathematical meaning ${ }^{13} \gg$. We should take into account for this passage that in 1948 about twenty years of hard work had been invested by physicists and mathematicians to link quantum physics with special relativity. About the time of Weyl's talk the young generation of theoretical physicists were just achieving a decisive step forward with renormalizable quantum electrodynamics ${ }^{14}$, whereas the wider perspective of a synthesis of gravitation and quantum physics was still deeply covered by some barely identifiable « fog-bank ».

At this place, Weyl made a short excursion to the outlook of Gonseth's philosophy, as presented, e.g. in «Die Dialektisierung der Erkenntnis ${ }^{15}$ » : « The call for a dialectization of knowledge rings out from Zurich. It is not completely clear to me what this means ${ }^{16}$. »

He agreed with Gonseth that modern science continues to create a theoretical image of the world, although this image and the language in which it is formulated is no longer restricted by any fixed a priori but is shaped by scientific experience and « its interpretations (Deutungen) which are forced upon it by the context of science itself». Although Gonseth had, of course, analyzed the epistemic role of some of these Deutungen in a stronger sense than Weyl presented in this short reference, i.e. as « constitutive schemata » in knowledge production ${ }^{17}$, Weyl essentially agreed with Gonseth thus far. But, in the evaluation of the range of the change from the formerly fixed a priori to the constructed constitutive schemata, he had a difference that he frankly stated : « But this free outlook, which does justice to the interaction between construction and reflection, probably does not yet deserve the label of dialectic ${ }^{18}$. »

Such a critical remark was not at all dismissive with respect to dialectical thought, as one might expect from a mathematical scientist active in one of the « two cultures » of the $\mathrm{XX}^{\text {th }}$ century ${ }^{19}$. As distinct from most of the contemporary scientists and mathematicians,

11. WEYL, 1948, p. 299.

12. WEYL, 1948, p. 299.

13. WEYL, 1948, p. 338.

14. SCHWEBER, 1994.

15. Gonseth, 1943.

16. WEYL, 1948, p. 339.

17. Heinzmann, 1982, p. $89 \mathrm{ff}$.

18. WEYL, 1948, p. 339.

19. SiguRdSSON, 2001. 
Weyl had become acquainted with the dialectical philosophy of (post-Kantian) German idealism in his early Zurich years under the influence of Medicus, and had, in particular, intensely studied Fichte's Wissenschaftslehre. As a result, he requested from a proper dialectic that it should be richer in the interplay of internal oppositions than just allowing for conceptual shifts in the historical development of knowledge systems. Following a short presentation of Gonseth's discussion of the concept of velocity and its modification by relativity, he commented :

"In the new relativistic picture the original concepts are "lifted" (aufgehoben) in Hegel's double meaning of the word. That may be accurate in the historical sense, but even then it would only be a "historical" dialectic ${ }^{20}$. »

In the late 1940s, Weyl had distanced himself considerably from Fichte. As he explicitly stated, he now sympathized with another version of dialectical thought, « existential philosophy, e.g. in the Heideggerian form ${ }^{21} »$. To hint, at least at the direction in which he looked for a connection between existentialist philosophy and modern science, Weyl presented a simple but strong consideration that would counteract or even prevent any attempt to strive for a new reductionistic world picture.

He reminded his audience that quantum physics (QP) posed a much more fundamental riddle than relativity theory (RT). In RT the classical concepts of kinematics and dynamics were «lifted $»$ in a way that allowed a reconstruction and understanding of prerelativistic thought, well defined mathematically and physically. Critically reflecting the Copenhaguen interpretation of quantum mechanics from his point of view, he contrasted this well defined conceptual connection in RT with the dilemma outlined by Bohr for QP, which arose from the necessity to represent the « hidden physical process », by a mathematical symbolism dissociated from classical physics and everyday experience. On the other hand he declared that «natural understanding of the world and the language in which it is expressed » is necessary for the process of measurement and observation and its description, « perhaps slightly purified and clarified (gereinigt und geklärt) by classical physics ». He saw no possibility for a complete theory of measurement and observation in terms of QP. On the assumption that such a difference might continue to hold in the future, he commented :

« Then we had, here, a true dialectic, impossible to lift by any historical development : the hidden soil (der dunkle Boden) [of everyday life and natural language] can be illuminated from the higher viewpoint of quantum physics, but it remains the ground (Grund) that cannot be dissolved into the light of the higher region ${ }^{22}$. »

Such an unresolvable opposition reminded Weyl of a comparable one in existential philosophy. There the Dasein (being-there) as the form of being, which includes self-awareness, is achieved by human beings rising to consciousness of themselves. On the other hand the same process necessarily led to a «burial of the external world in nothingness », and thus made it necessary later to «prove» the latter indirectly. The

20. WEYL, 1948, p. 339.

21. WEYL, 1948 , p. 343.

22. WeYL, 1948, p. 340-341. 
rise of human cognition to a rationalist self-consciousness of an individual (Cartesian) self, led necessarily to what Weyl now called the «problem of the external world (Problem der Aussenwelt) ${ }^{23}$ ». « [O]ne attempts to glue the isolated subject left behind to the disconnected patches of the world, but it remains a patchwork ${ }^{24}$. »

Although Weyl admitted that his argument for comparability between the different oppositions in QP and existential philosophy had no compelling power, he nevertheless insisted on the value of the problem posed by this observation. Moreover, he indicated how the existential split between the clarity of self-conscious being-there (Dasein) and the dark patches of insight of the external world might be resolved, not by a progression in pure thought, but by a transition to another way of life and being, in which the self might be perceived as part of a communicating web of self-conscious beings and the broader world in which they live.

«In understanding myself as being-together-with (seiend-mit) I also understand different being-there (Dasein). This is not, however, a knowledge achieved and concluded by new cognition, but a primary existential way of being that is the conditio sine qua non for cognition and knowledge ${ }^{25}$. »

We find other notes and speeches which show that, after the experience of the destructive powers unleashed by World War II, existential philosophy had become for Weyl a medium of reflection not necessarily leading to consequences for scientific knowledge, but endowed with a value of its own. Thirty years earlier in his life, in his encounter with Fichte's philosophy during and shortly after World War I, things had been slightly different in this respect. Weyl had been attracted by philosophical considerations as a young man, but at that time he tried to connect his newly-gained philosophical convictions to his ongoing scientific research.

\section{FICHTE'S DIALECTICAL CONSTRUCTION OF THE CONCEPT OF SPACE}

In his glance back at his intellectual life, «Erkenntnis und Besinnung ${ }^{26} »$, Weyl recounted his turn towards Fichte's Wissenschaftslehre under the influence of Medicus. He admitted to having been seized by Fichte's idealist metaphysics, although he had been lucky enough to find a counterweight in Helene's (his wife's) more sober style of thought, shaped by Husserl's phenomenology : «I had to concede to her that Fichte, by his stubbornness in pursuing an idea, blind to nature and facts, was swept away into increasingly abstruse constructions ${ }^{27}$. » On the other hand, he had been impressed and

23. WeYL, 1948, p. 343. This formulation is close in language and content to the «problem of matter (Problem der Materie) » that Weyl had encountered in the later 1920s, after he had given up the reductionist idea of deriving matter structures, in a Mie-type approach, from pure (classical) field theory.

24. WEYL, 1948 , p. 344.

25. WEYL, 1948, p. 344.

26. WEYL, 1954.

27. WEYL, 1954, p. 637. 
attracted by Fichte, whom in 1954 he still esteemed as a « constructivist of the purest water, who pursues his independent path of construction without looking right or left ${ }^{28}$ ».

This characterization gives a clue as to why the young mathematician Weyl was attracted by Fichte in the years between 1916 and 1921. At that time Weyl did not refer much to Fichte in his publications; nevertheless he did not completely hide the attraction and sympathy he felt for Fichte's philosophy. On the first pages of Das Kontinuum, he discussed the difficult problem of a philosophically satisfying clarification of the foundations of logic and confessed :

« We cannot hope to give here a final clarification of the essence of fact, judgement, object, property ; this task leads into metaphysical abysses ; about these one has to seek advice from men whose name cannot be stated without earning a compassionate smile (mitleidiges Lächeln) - e.g. Fichte ${ }^{29}$. »

At the time more esteem could be expected among mathematicians, in particular from the Göttingen milieu, from references to Husserl's philosophy. Thus we find more frequently public references to Husserl's Phänomenologie than to Fichte's Wissenschaftslehre, initially restricted, however, to the discussion of the problem of time and Husserl's Ideen zu einer reinen Phänomenologie ${ }^{30}$. After Weyl had formulated his « purely infinitesimal » geometry, he looked for a more philosophical underpinning of his new geometry, and proceeded, in 1920 and the following years, to an a priori derivation of its structure by what he then called the mathematical analysis of the problem of space (mathematische Analyse des Raumproblems). His turn of thought coincided with the publication of Husserl's altered (second) edition of Logische Untersuchungen in the years 1921 (Bd II) and 1922 (Bd I). Paolo Mancosu and Thomas Ryckman argue that Weyl only then started to read the latter with some care. In fact, in a letter-of-thanks (March 26-27, 1921) for the gift of the second edition of the Logische Untersuchungen by its author, Weyl wrote to Husserl that he had « only now » been able to get some « superficial » acquaintance with the book's content ${ }^{31}$.

When he included a first sketch of his investigations on the Raumproblem in the fourth edition of Raum, Zeit, Materie it appeared fitting to him to declare his recent investigations to be an «analysis of essence » as attempted by phenomenological philosophy («von der phänomenologischen Philosophie (Husserl) angestrebte Wesensanalyse $32 »)$. This remark included, now, a global and non-explicit reference to Husserl's Logische Untersuchungen ${ }^{33}$. We had better abstain, however, from reading into it a long-range impact of Husserl's phenomenology on Weyl's own researches ${ }^{34}$. His letter

28. WEYL, 1954, p. 641.

29. WEYL, 1918a, p. 2.

30. WEYL, 1918b, p. 133. References in WEYL, 1918a, p. IV, and at the beginning of WEYL, 1918b, p. 4 , footnote 1 .

31. HuSSERL, 1994, p. 290.

32. WEYL, 1918b, p. 133.

33. HUSSERL, 1900-1902.

34. The dialogue between Weyl and Husserl may also have found expression the other way round. In the $2^{\text {nd }}$ ed. of Bd II of Logische Untersuchungen, we find interesting discussions of the Idee der reinen Mannigfaltigkeitslehre and the division of labour among mathematicians/scientists and philosophers, see HuSSERL, 1900-1902, here Bd II, $2^{\text {nd }}$ ed. 1921, p. $258 \mathrm{ff}$. 
to Husserl was written three to four years after Weyl's first fundamental contributions to the foundations of mathematics and « purely infinitesimal geometry » (gauge geometry) in 1918, nearly two years after his « conversion » to Brouwer's intuitionism, and at a time when he was coming close to the end of his most radical phase in foundations of mathematics and unified field theory based on a dynamistic natural philosophy. At this time the «mathematical analysis of the problem of space » opened up for him a path towards a continuation of his interest in gauge geometrical structures without a necessary link to a purely field theoretic (Mie type) explanation of matter. Even taking into account the appropriate modesty of Weyl as a scientific correspondent with respect to the professional philosopher, we find here a convincing additional evidence for Weyl's own later evaluation that, although Husserl's phenomenological philosophy had helped him in finding a path towards a « freer view of the world » than the positivist one, it had not been the strongest intellectual reference for him during his years of Sturm and Drang 35 .

As I have already argued on another occasion ${ }^{36}$, Fichte's dialectical construction of the concept of space seems to have been of more importance for the development of Weyl's research orientation in this early, philosophically radical, phase of his work. In order to make the argument more accessible (and thus criticizable), I want to give a short outline of some features of Fichte's philosophy as a « radical constructivist » at work in (dialectically) constructing the concept of space, both topics close to Weyl's mind in the years between 1916 and $1920^{37}$.

Fichte considered dialectics as the form of movement in the self-construction of thought, and described this conception in words that came to meet Weyl's needs in his search for intellectual orientation and support in the «metaphysical abysses » of the philosophical clarification of the foundations of logic. Fichte explained, e.g., in this context that he was not keen to develop the «dialectics of making up or inventing something (die Dialektik des Aus-oder Erdenkens) »; he wanted to achieve a way of organizing the thought process in a way such that «we are seized by evidence ». This was, according to Fichte, the task of a «true dialectic ».

«Ingenuity gives only sudden evidence which can vanish again; true dialectic is the lawful method to achieve evidence. [...] Construction is now the instruction to invent the concept by the imaginative power, such that evidence may be gained ${ }^{38}$. »

A comparable claim for a direct link between construction and evidence runs like a continuous thread through Weyl's radical writings on the foundations of analysis; in fact, on the level of basic methodological convictions, it unites the different, more

35. WeYL, 1954, p. 637.

36. SCHOLZ, 1995.

37. See also the remarks on Fichte in DA Silva, 1997.

38. Fichte, 1834, p. 188 : «Dies ist nicht die Dialektik des Aus- und Erdenkens, sondern das Denken macht sich uns selbst, die Evidenz ergreift uns. Durch Genie nur plötzliche Evidenz, die wieder entschwinden kann; wahre Dialektik aber die gesetzmäßige Methode, zu dieser Evidenz zu kommen. Die Kunst der Dialektik, wie alle Kunst, ist unendlich; nicht aber die Wahrheit. Construction ist nun die Anleitung, durch die Einbildungskraft den Begriff zu erfinden, daß die Evidenz sich einstelle. Es giebt da gleichsam eine ursprüngliche, und nach dieser ringen wir. Wie in der Mathematik: nicht die Wahrheit wird gemacht, sondern nur der Vortrag der Wahrheit. » (Emphasis in the original.) 
technical positions which he adhered to between 1916 and 1920/1921, from the predicative, arithmetico-logical foundation in Das Continuum ${ }^{39}$ to the (quasi-)intuitionistic strategy of the article « Über die neue Grundlagenkrise der Mathematik ${ }^{40}$ ».

As a philosophical resource of inspiration for Weyl, Fichte's construction or « derivation » of the concept of space seems to have been of far larger range. I sketch the most important features (in the Weylian context) following Fichte's exposition in the Grundriß $\beta$ des Eigenthümlichen der Wissenschaftslehre ${ }^{41}$.

Fichte started from two opposing, initially separated, « external perceptions, $i$ e. perceptions of appearances, $X$ and $Y$ (Fichte's own symbolism ${ }^{42}$ ). As appearances $X$ and $Y$ were, for Fichte, expressions of two forces that had to be assumed «necessarily ${ }^{43}$ ». Space was then developed by Fichte as the « initially still unknown » external determination of the possible relations between $X$ and $Y$ (i.e., in particular not generated by the interior determinations of the appearances $X$ and $Y$ ). For this determination (which later in the development - or « construction » - would become space), he introduced the formal symbol $O$.

Now, the «mode how $X$ is thus determined », i.e. by its relation to the totality of possible relations, may be symbolized as $x$, and the « mode how $Y$ is thus determined » as $y$. In this way, Fichte introduced symbols of external positioning $x$ and $y$ for the appearances $X$ and $Y^{44}$, and emphasized that the relation between $X$ and $Y$, and thus $O$ (the concept of space in generation), could « by no means be derived from the self, but must be attributed to the things themselves ${ }^{45}$ ».

Fichte continued his argumentation that $X$ and $Y$ suffer « exclusion and continuity » (Ausschließung und Continuität) and that by such an interplay a «common sphere » is generated $^{46}$.

For the concept of space in generation Fichte postulated : « $O$ must be something which leaves the liberty of both $[X$ and $Y]$ in their activity completely undisturbed ${ }^{47}$. »

Correspondingly, the external positionings $x$ and $y$ then represent also « spheres of activity » (Sphären der Wirksamkeit) of the forces « assumed necessarily » for the appearances $X$ and $Y$. These must not, initially, be considered from an extensional point of view, i.e. spacelike. Only after the formation of a «common sphere » of both « $[O$ will be...] posited (gesezt) (sic) as extended, connected, infinitely divisible and is Space $^{48}$. »

39. WEYL, 1918a.

40. WeYL, 1921.

41. FICHTE, 1795.

42. Fichte, 1795, p. 194.

43. Fichte, 1795, p. 197.

44. In fact, Fichte used different small letters, $z$ and $v$, in place of our $x$ and $y$, which we use here for mnemonic reasons.

45. Fichte, 1795, p. 195.

46. FICHTE, 1795, p. 196 : «Es wird demnach durch absolute Spontaneität der Einbildungskraft eine solche gemeinschaftliche Sphäre producirt (sic). »

47. FichTE, 1795, p. 198. To readers acquainted with Weyl's analysis of the problem of space, a striking similarity to the latter's « postulate of freedom » may come to mind, when reading this Fichtean step.

48. Fichte, 1795, p. 200. 
Once the concept of space has been derived, the positions ( $x$ and $y$, etc.) are to be understood as result of an infinite division of space, as « infinitely smallest parts of space ». Fichte was quite definite, though, that such parts could not be considered as points : «The infinitely smallest part of space is always a space, something endowed with continuity, not at all a mere point or the boundary between specified places in space ${ }^{49}$. »

In these infinitesimal parts ${ }^{50}$ the "imaginative power ${ }^{51}$ » (Einbildungskraft) puts up a force which expresses itself «with necessity». Fichte thus arrived at a common conceptualization of space and systems of forces that went far beyond the Kantian dynamistic concept of matter in the Metaphysische Anfangsgründe der Naturwissenschaften. «Thus intensity [here : force] and extensity [space] are by necessity synthetically united, and one must not try to discuss the one without the other ${ }^{52}$. »

Fichte concluded : «Each force, by its necessary product, fills [...] a place in space ; and space is nothing but that which is filled or to be filled by these products ${ }^{53}$. » I have already said that «places in space » (Stellen im Raume) were not to be considered as points but as « infinitely smallest parts ${ }^{54}$.

To summarize, Fichte « constructed » a concept of space starting from « spheres of activities » $(x, y$, etc. $)$ of appearance $(X, Y \ldots)^{55}$; the system $O$ of possible external relations of these was «posited $»$ as « continuous, connected, and infinitely divisible ${ }^{56}$. Integration of the conceptual structure transformed the spheres of activities $(x, y \ldots)$ into infinitesimal parts of $O$, which thus became the symbol and concept of space. The infinitesimal parts were carriers of forces which Fichte considered as the primordial space-filling structures.

In slightly more mathematical language we find here a clear and beautiful affinity to three essential topics in Weyl's « purely infinitesimal geometry » and his first unified gauge field-and-matter theory of $1918^{57}$ :

- construction of a spacelike continuum from infinitesimal parts (not as a set of points, endowed only in an additional step with a continuous, differentiable, etc. structure, as intended - not yet achieved - by mainstream mathematics of the time),

- characterization of the space-filling entities as forces, the actions of which were initially specified only in the infinitesimal parts (Weyl's postulate to build geometrical structures « purely infinitesimally »),

- formation of matter as a form of appearance of space-filling forces (dynamical theory of matter, going back to Kant and mathematically rejuvenated by Mie and Hilbert).

49. FICHTE, 1795, p. 200.

50. «Infinitesimal » is a word introduced by me (ES) not by Fichte, although the concept is.

51. Probably of the « absolute self ».

52. FichTE, 1795, p. 201.

53. FICHTE, 1795, p. 201.

54. FICHTE, 1795, p. 200.

55. FICHTE, 1795, p. 200.

56. FICHTE, 1795, p. 200.

57. On this background it does not come as a great surprise that Tonietti, in his excursion into Weyl's « purely infinitesimal » geometry, realizes at the height of his exposition of this point that he apparently lost contact with Husserl, and that he had better come back to the question of Zeitbewußtsein, in order to « again encounter Husserl who otherwise might be forgotten », see TONIETTI, 1988, p. 366. 
WEYL'S « PURELY INFINITESIMAL GEOMETRY » AND HIS FIELD/MATTER THEORY OF 1918

In order not to be misunderstood, I want to state the obvious in advance: Weyl's purely infinitesimal geometry and (gauge) field theory of 1918 were, of course, much more than a mere transformation of Fichtean ideas into mathematics and physics. There was a substantial and complex background in the mathematical and physical knowledge of the time, deeply shaped by the work of Albert Einstein and extended by Gustav Mie, David Hilbert, Tullio Levi-Civita, and others ${ }^{58}$. The intellectual work to be done was too demanding and technically too cumbersome, to allow such a (bad) reduction. In addition, our mathematician was confronted with the beneficial warnings of Helene Weyl not to follow Fichte's « obstinacy, blind to nature and facts ${ }^{59}$ », in pursuing his ideas, without sufficient reflection and intellectual distance. The overenthusiastic language in key publications of the years 1918 to 1921 shows that he was, in fact, in such a danger. He experienced these years of social and political disorder as a time of cultural crisis, and was all the more longing for a path towards an alleged transcendent order ${ }^{60}$.

Already by November 1917, when he finished his work on Das Kontinuum with its predicative construction of the arithmetically definable subset of the classical real continuum, Weyl was dissatisfied with his own theory ${ }^{61}$. In public he compared it with Husserl's discussion of the continuum of time, which had a «non-atomistic » character, in drastic contrast to his own theory. No determined point of time can be exhibited, only approximative fixing is possible, just as is the case for « the continuum of spatial intuition » (Kontinuum der räumlichen Anschauung ${ }^{62}$ ). Fichte had insisted on the same feature, as Weyl knew well at the time, but preferred not to touch upon explicitly at this place. However, he himself also accepted the necessity that the mathematical concept of continuum, the continuous manifold, should not be characterized in terms of modern set theory enriched by topological axioms (and axioms for coordinate systems), because this would contradict the concept (the « essence » as Weyl liked to claim) of the continuum. He continued to insist on this methodological principle even after softening his radical position or even turning away from it. In a paper written in 1925, although published only posthumously, we find, perhaps, the clearest expression of this Weylian conviction with respect to the set-theoretic approach to manifolds :

«It seems clear that it [set theory] violates against the essence of the continuum, which, by its very nature, can not at all be battered into a set of single elements. Not the relationship of an element to a set, but of a part to the whole ought to be taken as a basis for the analysis of the continuum ${ }^{63}$. »

58. For a comprehensive view, see Vizgin, 1994, STACHEL, 1995, CAO, 1997 ; for Mie and Hilbert, see CORRY 1999a, CORRY 1999b, CORRY 2004.

59. WeYL, 1954, p. 637.

60. SigURDSSON, 2001.

61. For Weyl's 1918 approach to foundations of analysis, see FefERman, 2000, Coleman and KorTÉ, 2001, p. 315ff. ; for a discussion of his shifts in foundations, see ScHOlz, 2000.

62. WeYL, 1918a, p. 70f.

63. WeYL, 1925/1988, p. 5. 
For Weyl, single points of a continuum were empty abstractions; an acceptable abstraction would arise only from a limiting procedure of localization inside a continuum :

«The mf. is continuous, if the points are fused together in such a manner that it is impossible to display a single point, but always only together with a vaguely limited surrounding halo (Hof), with a "neighbourhood" 64 . "

With such a conception Weyl entered difficult terrain, as no mathematical conceptual frame was in sight, which could satisfy his methodological postulate in a sufficiently elaborate way. For some years Weyl sympathized with Brouwer's idea to characterize points in the intuitionistic one-dimensional continuum by « free choice sequences » of nested intervals ${ }^{65}$. He even tried to extend the idea to higher dimensions and explored the possibility of a purely combinatorial approach to the concept of manifold, in which point-like localizations were given only by infinite sequences of nested star neighbourhoods in barycentric subdivisions of a combinatorially defined «manifold ». There arose, however, the problem of how to characterize the local manifold property in purely combinatorial terms. Although Weyl outlined a strategy to, possibly, overcome this problem, his approach remained essentially without long-range effects in $\mathrm{XX}^{\text {th }}$-century topology.

Weyl was much more successful on another level of investigation, in his attempts to rebuild differential geometry in manifolds from a « purely infinitesimal » point of view. He generalized Riemann's proposal for a differential geometric metric

$$
d s^{2}(x)=\sum_{i, j=1}^{n} g_{i j}(x) d x^{i} d x^{j}
$$

From his purely infinitesimal point of view, it seemed a strange effect that the length of two vectors $\xi(x)$ and $\eta\left(x^{\prime}\right)$ given at different points $x$ and $x^{\prime}$ can be immediately (and in this sense « objectively ») compared in this framework after the calculation of

$$
|\xi(x)|^{2}=\sum_{i, j=1}^{n} g_{i j}(x) \xi^{i} \xi^{j}, \quad\left|\eta\left(x^{\prime}\right)\right|^{2}=\sum_{i, j=1}^{n} g_{i j}\left(x^{\prime}\right) \eta^{i} \eta^{j} .
$$

In this context, it was comparatively easy, for Weyl, to give a purely infinitesimal characterization of metrical concepts. He started from the well known structure of a conformal metric, i.e. an equivalence class $[g]$ of semi-Riemannian metrics $g=\left(g_{i j}(x)\right)$ and $g^{\prime}=\left(g_{i j}{ }^{\prime}(x)\right)$ which are equal up to a point dependent positive factor $\lambda(x)>0, g^{\prime}=\lambda g$. Then, comparison of length made immediate sense only for vectors attached to the same « point » $x$, independently of the « gauge » of the metric, i.e. the choice of representative in the conformal class. To achieve comparability of lengths of vectors inside each infinitesimal neighbourhood, Weyl invented the concept of «length connection » formed in analogy to the affine connection $\Gamma$, just distilled from the classical Christoffel

64. WEYL, 1925/1988, p. 2.

65. WEYL, 1921. More details of this aspect are given in ScHOLZ, 2000. 
symbols $\Gamma_{i j}^{k}$ of Riemannian geometry by Levi-Civita (and himself, as far as the abstraction from the metrical context is concerned) ${ }^{66}$. The localization inside such an infinitesimal neighbourhood was given, as would have been done already by the mathematicians of the past, by coordinate parameters $x$ and $x^{\prime}=x+d x$ for some « infinitesimal displacement » $d x$. Weyl's length connection consisted, then, in an equivalence class of differential 1-forms $[\varphi], \varphi=\sum_{i=1}^{n} \varphi_{i} d x^{i}$, where an equivalent representation of the form is given by $\varphi^{\prime}=\varphi-d \log \lambda$, corresponding to a change of gauge of the conformal metric by the factor $\lambda$. Weyl called this transformation, which he recognized as necessary for the consistency of his extended symbol system, the « gauge transformation » of the length connection. That was the first step towards the investigation of (generalized) connections in modern differential geometry, i.e. no longer necessarily in the linear group and derived from a Riemannian metric.

Weyl thus established a «purely infinitesimal» gauge geometry, where lengths of vectors (or derived metrical concepts in tensor fields) were immediately comparable only in the infinitesimal neighbourhood of one point, and for points of « finite » distance only after an integration procedure. This integration turned out to be, in general, path dependent. Independence of the choice of path between two points $x$ and $x$ ' holds if and only if the « length curvature » vanishes. The concept of curvature was built in direct analogy to the curvature of the affined connection and turned out to be, in this case, just the exterior derivative of the length connection : $f=d \varphi$. This led Weyl to a coherent and conceptually pleasing realization of a metrical differential geometry built upon « purely infinitesimal » principles. He explored some features of this geometry, which appeared of immediate importance to him : existence and uniqueness of a compatible affine connection, gauge behaviour (gauge invariance respectively « gauge covariance » specified by «gauge weight ») of tensors derived from the data $[g],[\varphi]$ of the Weylian metric, relationship to Riemannian manifolds, in particular different natural choices of gauge in the (semi-)Riemannian case, etc.

Moreover, Weyl was convinced of important consequences of his new gauge geometry for physics. The infinitesimal neighbourhoods understood as « spheres of activity », as Fichte might have said, suggested looking for interpretations of the length connection as a « field» representing physically active quantities. And in fact, building on the (mathematically obvious) observation $d f=0$, which (in coordinates) was formally identical with the second system of the generally covariant Maxwell equations, Weyl immediately drew the conclusion that the length curvature $f$ ought to be identified with the electromagnetic field. For Weyl this had some, initially equally, important consequences :

(1) Conservation of current appeared as a consequence of gauge.

(2) Conformal metric, the gauge principle, length connection and affined connection were part of a unified conceptually convincing structure.

(3) Gravitation (with its potential $g$ ) and electromagnetism (potential $\varphi$ ) were intrinsically unified and both identified with constitutive elements of the geometric structure.

66. See Reich, 1992, BottaZZini, 1999. 
(4) The Mie-Hilbert theory of a combined Lagrange function $L(g, \varphi)$ for the action of the gravitational field $(g)$ and electromagnetism $(\varphi)$ was further geometrized and technically enriched by the principle of gauge invariance (for $L$ ).

Weyl thus believed for a short while (from 1918 to summer 1920) that his gauge geometric modification of the Mie-Hilbert theory would finally show the path towards the blue flower of dynamism, i.e. an explanation of the stable structures of the elementary particles known at the time (electron and proton), the mathematical derivation of the basic stable composite configuration (atoms), at least in the simplest cases, and their energy levels (spectra).

He gave up the belief, however, in the ontological correctness of the purely fieldtheoretic approach to matter (point (4) above) in late summer 1920, substituting in its place a philosophically motivated a priori argumentation for the conceptual superiority of his gauge geometry (i.e. point (2)) during the following years (his analysis of the problem of space, 1920-1923) ${ }^{67}$. At the end of the 1920s he finally withdrew the metrical version of the gauge characterization of electromagnetism (point (3) above) and transformed it into the new form of a $U$ (1) gauge connection in the extended symmetries of a generally covariant formulation of the Dirac equation, which he proposed in $1929^{68}$. The gauge interpretation of current conservation (point (1)), finally, was upheld in the new form. In the early 1930s Pauli assimilated it to the knowledge of quantum physics, and it became, in a generalized form, a central methodological element in the self-construction of theoretical fundamental physics during the second half of the $\mathrm{xx}^{\text {th }}$ century ${ }^{69}$.

The goal of a unified description of gravitation and electromagnetism, and the derivation of matter structures from it, was nothing specific to Weyl. After 1915 it had become a hot topic in Göttingen, after Hilbert's incursion into general relativity ${ }^{70}$. Hilbert had built upon Mie's work, and Mie was fond of Kant's dynamistic approach to the problem of matter and other purely field-theoretic theories of the electron mass from the turn of the century. So Weyl's attempt at a unification was in its general perspective not at all foreign to the larger enterprise of contemporary mathematical physics and natural philosophy, at least in the scientific environment of Göttingen. In Weyl's theory, the « purely infinitesimal » approach to manifolds and the ensuing possibility to geometrically unify the two known interaction fields gravitation and electromagnetism, this perspective took on a particularly dense and conceptually sophisticated shape. Thus it may be not surprising, although perhaps a bit ironic, that Hilbert showed awareness of the «extreme idealization» of the geometric classical field theoretic approach to fundamental physics only after he could reflect on Weyl's sharpening of their common approach in the winter 1919-1920 ${ }^{71}$. Hilbert's surprise regarding Weyl's theoretical program which was so close in its goals to his own enterprise, only conceptually more densely knit, helped him, apparently, to reflect critically on the attempts to derive matter structures from classical fields. He now felt, that the «completed process of physical idealization » building upon classically deterministic mathematical structures

67. See Coleman and Korté, 2001, p. 215ff. ; SCHOlZ, 2001, p. $85 \mathrm{ff}$.

68. See Straumann, 2001 ; Vizgin, 1994, chap. v.

69. O'Raifeartaigh and StraumanN, 2000.

70. Vizgin, 1994, Corry, 1999a, Corry, 1999b, Corry, 2004, Renn and Stachel 1999, Rowe, 2000, GOLDSTEIN and RitTER, 2000.

71. HiLbert, 1992, p. $98 \mathrm{ff}$. 
would necessarily lead to what he now called pejoratively « Hegelian physics » ${ }^{72}$, as a label for an all-embracing complete determinism. Such a world view would necessarily run into the paradoxes of time inversion also holding for organic processes and, even stranger, the following effect :

«Decisions in the proper sense could not take place at all, and the whole world process would not transcend the limited content of a finite thought. [...] For the same reason also intellectual culture (das Geistige), in particular our thought, had to be something merely ephemeral (etwas bloß Scheinbares) - an absurd consequence for a view of nature which results from the attempt to make all elements of reality (Inhalte der Wirklichkeit) accessible to our thought ${ }^{73}$. »

Hilbert was thus struggling, like Weyl, with the problem of how classical determinism in the theory of nature could go in hand with a unifying world view. In his stubborn rejection of post-Kantian dialectical philosophy, expressed in his misled stereotype of « Hegelian physics », he pointed to a field that had served as a cultural background for Weyl. He apparently was not aware that in its concrete manifestation it was Fichte's philosophy and not Hegel's, which had inspired the scientific imagination of his former student ${ }^{74}$. Moreover, his polemics contain an unnoticed and unvoluntary self-ironic twist : Hilbert apparently did not realize that the verdict of a « Hegelian physics » might just as well, or even with stronger justification than to Weyl's program, be applied to his own theory ${ }^{75}$.

\section{WEYL'S LATE REFLECTIONS ON HEIDEGGER}

What Weyl owed to Fichte's philosophy cannot and should not be described as a «philosophical influence » on mathematics, not even in the slightly more restricted version of a presumed « influence » of Fichte's philosophy of space and force on differential geometry, foundations of mathematics, and/or field physics. Fichte's philosophy was, of course, no historical agent or even actor. Its role in the genesis of Weyl's contribution to infinitesimal geometry, the concept of continuum, and field theory is much more precisely described as that of a cultural resource which Weyl utilized. This perspective appears helpful for leaving behind the disciplinary boundaries in the investigation of the history of mathematics and science in general ${ }^{76}$. Not in all cases, however, could Weyl's resort to philosophers or philosophies be adequately described as a resource made serviceable in his scientific work. We have seen above, how Weyl referred to Heidegger's existentialist or Gonseth's dialectical philosophies in 1948. He was fond of, and probably needed, a broad reflection on his activities as part of a conscious embedding

72. HiLBERT, 1992, p. 100.

73. HiLBERT, 1992, p. 100f. (emphasis in original).

74. If Hilbert had known, he probably would not have cared.

75. ReNN and StACHEL, 1999, thus call Hilbert's original program of 1915ff. an attempt of a «theory of everything ».

76. I thank Skúli Sigurdsson who in our discussions insisted on such a distinction and emphasized, in particular, the « resource aspect » of philosophy for Weyl, see SIGURDSSON, 2001. 
in a cultural setting. Weyl considered such reflections as one part of a dyad on the other side of which he saw and practised scientific activity, «construction » as he liked to say. Although he talked about them in terms of «Besinnung " (contemplation), which sounds surprisingly inoffensive and harmonious, these reflections were not at all of a harmonizing and introspective nature.

Just to the contrary, Weyl was deeply bewildered by the great crises of the $\mathrm{Xx}^{\text {th }}$ century, World War I and the following revolutionary disturbances, the rise of Nazism in Germany, World War II with the holocaust and the « (let us hope short-lived) Nazification of the European continent ${ }^{77} »$, and the ensuing menace of nuclear destruction. The goal of his «Besinnung» was to cope with such disconcerting experiences and to find some defendable position towards them. Weyl's late turn towards Heidegger's philosophy is apparently an expression of the experience of being « cast » into a world that had turned out to be socioculturally unreliable and had developed strong features of destructiveness. Perhaps the strongest expression of his deep cultural doubts at this time can be found in a manuscript on « The development of mathematics since $1900^{78}$ », in which he drew a parallel between Aristotle's characterization of metaphysics and of his own thoughts about modern mathematics :

« Here some words of Aristotle come to my mind which, to be true, refer to metaphysics rather than mathematics. Stressing its uselessness as much as Hardy does in his apology of mathematics, but at the same time its divinity, he says (Metaphysics 982b) : "For this reason its acquisition might justly be supposed to be beyond human power ; since in many aspects human nature is servile ; in which case, as Simonides says, 'God alone can have this privilege', and man should only seek the knowledge which is of concern to him ( $\left.\tau \dot{\nu} \nu \varkappa \alpha \vartheta^{\prime} \alpha \dot{v} \tau \dot{v} v \varepsilon^{\prime} \pi \iota \sigma \tau \eta^{\prime} \mu \eta \nu\right)$. Indeed if the prets are right and the Deity is by nature jealous, it is probable that in this case they would be particularly jealous

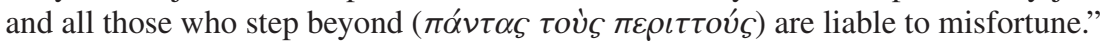

«I am not so sure whether we mathematicians during the last decades have not "stepped beyond" the human realm by our abstractions. Aristotle, who actually speaks about metaphysics rather than mathematics, comforts us by hinting that the envy of the Gods is but a lie of the prets ("prets tell many a lie" as the proverb says).

«For us today the idea that the Gods from which we wrestled the secret of knowledge by symbolic construction will revenge our $\tilde{v} \beta \rho \iota s$ has taken on a quite concrete form. For who can close his eyes against the menace of our self-destruction by science ; the alarming fact is that the rapid progress of scientific knowledge is unparalleled by a congruous growth of man's moral strength and responsibility, which has hardly a chance in historical time ${ }^{79}$.»

Thus Weyl's «Besinnung » did not at all avoid or compensate for uncomfortable experiences. He posed and presented problems arising in mathematics, culture and society as sharply as he could. Although he feared the menace arising from what he, in his educated language shaped by the classical humanist tradition, called the « hubris » of modern mankind, he did not give up the hope that another mode of (existential)

77. See Hermann Weyl to Alvin Johnson, March 22, 1941, in Siegmund-Schultze, 2001, p. 284 f.

78. WeYL, 1949a. English in original.

79. WEYL, 1949a, p. $6 f$. 
being might be possible. In his formulation inspired by Heidegger, cited at the beginning of this article, he specified this mode as that of seiend-mit, of being-together-with. For Weyl, remarks such as the one just cited show that he longed for a moral quality of being together which we might prefer to call a mode of conviviality using the later terminology proposed by Ivan Illich ${ }^{80}$. From Weyl's perspective, such a mode of convivial being and life might in turn contribute to the self-understanding of science and become part of the scientific enterprise, although in this case too he felt only faint « contours » of such a hope, outbalanced by the fear expressed at the end of our last quotation. Nothing assured or assures us of the success of a turn in this direction, however necessary it may be.

Erhard SCHOLZ ${ }^{*}$

(November 2004).

80. ILlich, 1973. We can thus express a distinction to a purely Heideggerian background. That seems appropriate, because the person Martin Heidegger was too closely affiliated with Nazi politics, at least in the first years after their rise to power, to accept that he and his philosophy might have become, without specifications, a morally attractive point of reference for Weyl in 1948.

* I thank John Stachel and Skúli Sigurdsson for discussions and critical remarks to earlier versions of the paper and for their linguistic support. The organizers of the conference at Crêt Bérard gave me the opportunity to present the remarks on Weyl to a predominantly philosophical audience. Archival material of the Weyl Nachlass was made accessible through the kind permission of Dr Michael Weyl by the team of the Handschriftenabteilung of the ETH Zurich. 


\section{LIST OF REFERENCES}

BotTAZZINI (Umberto), 1999, «Ricci and Levi-Civita. From differential invariants to general relativity », in GRAY, 1999, p. 241-259.

CAO (Tian Yu), 1997, Conceptual developments of $x^{t h}$-century field theories, Cambridge, Cambridge University Press.

Coleman (Robert) and Korté (Herbert), 2001, «Hermann Weyl. Mathematician, physicist, philosopher », in SCHOLZ, 2001, p. 161-388.

CORRY (Leo), 1999a, «David Hilbert between mechanical and electromagnetic reductionism (1910-1915) », Archive for History of Exact Sciences, vol. LIII, 6, p. 489-527.

CORRY (L.), 1999b, « From Mie's electromagnetic theory of matter to Hilbert's unified foundations of physics », Studies in History and Philosophy of Modern Physics, vol. XXX, p. 159-183.

CORRY (L.), 2004, David Hilbert and the axiomatisation of physics (1898-1918). From Grundlagen der Geometrie to Grundlagen der Physik, Dordrecht, Kluwer.

DA SILVA (Jairo J.), 1997, « Husserl's phenomenology and Weyl's predictivism », Synthese, 110, p. 277-296.

DEPPERT (Wolfgang) et al., ed., 1988, Exact Sciences and their philosophical foundations, Kiel, Internationaler Hermann-Weyl-Kongress, 1985, Frankfurt/Main, Peter Lang.

FEFERMAN (Solomon), 2000, "The significance of Weyl's Das Kontinuum », in Hendricks, Pedersen and JøRGENSEN, ed., 2000, p. 179-194.

FICHTE (Johann Gottlieb), 1795, Grundriss des Eigenthümlichen der Wissenschaftslehre in Rücksicht auf das theoretische Vermögen, Jena/Leipzig, Gesammelte Werke, Bd I, p. 331-411, here Gesammelte Abhandlungen, Stuttgart-Bad Cannstatt, Frommann-Holzboog, 1988-2001, Bd I.3, p. 142-208.

Fichte (J. G.), 1834, Einleitung in die Wissenschaftslehre. Nachgelassene Werke, Bd I, Bonn, Adolph Marcus, here repr. Berlin, W. de Gruyter, 1962.

GOLDSTEIN (Catherine) and RITTER (Jim), 2000, « The varieties of unity. Sounding unified theories 1920-1930 », Berlin, Max Planck Institut für Wissenschaftsgeschichte (Preprint, 149).

GonsETH (Ferdinand), 1943, Die Dialektisierung der Erkenntnis, Zurich, ETH (Kultur- und Staatswissenschaftliche Schriften).

GraY (Jeremy), ed., 1999, The Symbolic Universe. Geometry and physics, 1890-1930, Oxford, Oxford University Press.

HEINZMANN (Gerhard), 1982, Schematisierte Strukturen. Eine Untersuchung über den "Idoneismus » F. Gonseths auf dem Hintergrund eines konstruktivistischen Ansatzes, Bern/Stuttgart, Paul Haupt.

Hendricks (Vincent F.), Pedersen (Stigandur) and Jørgensen (Klaus F.), ed., 2000, Proof Theory. History and philosophical significance, Dordrecht, Kluwer.

HiLberT (David), 1992, Natur und mathematisches Erkennen. Vorlesungen, gehalten 1919-1920 in Göttingen, nach Ausarbeitungen von Paul BERnAYs, Hrsg. David Rowe, Basel, Birkhäuser.

HUSSERL (Edmund), 1900-1902, Logische Untersuchungen, Halle, Niemeyer; Bd II, teilweise umgearbeitete Auflage, Halle, Niemeyer, 1921 ; Bd I, 2. Auflage, Halle, Niemeyer, 1922 ; repr. in Husserliana, XIX, The Hague, Martinus Nijhoff, 1984.

HUSSERL (E.), 1913, Ideen zu einer reinen Phänomenologie und phänomenologischen Philosophie, Jahrbuch für Philosophie und Phänomenologische Forschung, Bd I ; 2. und 3. Auflagen, 
Halle, Niemeyer, 1922 und 1928 ; überarbeiteter Neudruck in Husserliana, III, The Hague, Martinus Nijhoff, 1950.

Husserl (E.), 1994, Briefwechsel. Bd VII : Wissenschaftlerkorrespondenz, Dordrecht, Kluwer. ILlich (Ivan), 1973, Tools for conviviality, $1^{\text {st }}$ ed. New York, Harper and Row, French, Paris, Seuil, 1973, German, Hamburg, Rowohlt, 1980.

MAnCosu (Paolo) and RYcKman (Thomas), 2002, « Mathematics, physics, and phenomenology. The correspondence between Oskar Becker and Hermann Weyl », Philosophia Mathematica, vol. X, p. 130-202.

O'Raifeartaigh (Lochlainn) and Straumann (Norbert), 2000, « Gauge theory. Historical origins and some modern developments », Reviews of Modern Physics, vol. LXXII, p. 1-23.

REICH (Karin), 1992, « Levi-Civitasche Parallelverschiebung, affiner Zusammenhang, Übertragungsprinzip, 1916/1917-1922/1923 », Archive for History of Exact Sciences, vol. XLIII, p. 77-105.

RENN (Jürgen) and STACHEL (John), 1999, « Hilbert's foundations of physics. From a theory of everything to a constituent of general relativity », Berlin, Max Planck Institut für Wissenschaftsgeschichte (Preprint, 118).

Rowe (David), 2000, « Einstein meets Hilbert. At the crossroads of physics and mathematics », Mainz, preprint.

Scholz (Erhard), 1995, « Hermann Weyl's "Purely Infinitesimal Geometry" », in Proceedings of the international congress of mathematicians, Zürich, Switzerland, 1994, Basel, Birkhäuser, p. 1592-1603.

Scholz (E.), 2000, « Hermann Weyl on the concept of continuum », in HendRICKS, Pedersen and JøRGENSEN, ed., 2000, p. 213-237.

Scholz (E.), ed., 2001, Hermann Weyl's Raum-Zeit-Materie and a general introduction to his scientific work, Basel, Birkhäuser.

Schweber (Silvan S.), 1994, QED and the men who made it. Dyson, Feynman, Schwinger and Tomonaga, Princeton, Princeton University Press.

SiEGMUND-Schultze (Reinhard), 2001, Rockefeller and the internationalization of mathematics between the two world wars, Basel, Birkhäuser.

SiguRDSSON (Skúli), 2001, « Journeys in spacetime », in SCHOLZ, 2001, p. 15-47.

STACHEL (John), 1995, « History of relativity », in PIPPARD (Brian), BROWN (Laurie) and PAIS (Abraham), Twentieth-Century Physics, vol. I, Bristol/Philadelphia/New York, Institute of Physics Publishing, chap. IV, p. 249-356.

STRAumann (Norbert), 2001, «Ursprünge der Eichtheorien », in Scholz, 2001, p. 138-160.

TIESZEN (Richard), 2000, « The philosophical background of Weyl's mathematical constructivism », Philosophia Mathematica, vol. VIII, p. 274ff.

Tonietti (Tito), 1988, « Four letters of E. Husserl to H. Weyl and their context », in DePPERT et al., 1988, p. 343-384.

VAN DaLen (Dirk), 1984, «Four letters from Edmund Husserl to Hermann Weyl », Husserl Studies, vol. I, p. 1-12.

Vizgin (Vladimir), 1994, Unified Field Theories in the first third of the XX $x^{\text {th }}$ century, transl. from the Russian by Julian B. BARBOUR, Basel, Birkhäuser.

WeYl (Hermann), 1918a, Das Kontinuum. Kritische Untersuchungen über die Grundlagen der Analysis, Leipzig, Veit.

WeYl (H.), 1918b, Raum, Zeit, Materie, $1^{\text {st }}$ ed. Berlin, here $4^{\text {th }}$ ed. Berlin, Springer, 1921.

WeYL (H.), 1921, « Über die neue Grundlagenkrise der Mathematik », Mathematische Zeitschrift, Bd X, p. 39-79, here repr. Gesammelte Abhandlungen, Berlin, Springer, 1968, vol. II, p. $143-180$.

WEYL (H.), 1925/1988, Riemanns geometrische Ideen, ihre Auswirkungen und ihre Verknüpfung mit der Gruppentheorie, Berlin, Springer (le manuscrit de ce texte date de 1925). 
WeYl (H.), 1927, « Philosophie der Mathematik und Naturwissenschaft », Handbuch der Philosophie, Abt. 2A, weitere Auflagen, Philosophie der Mathematik und Naturwissenschaft, $2^{\text {nd }}$ ed. $1949,3^{\text {rd }}$ ed. 1966, München, Oldenbourg, English with comments and appendices, in WEYL, 1949b.

WeYL (H.), 1948, «Wissenschaft als symbolische Konstruktion des Menschen », Eranos-Jahrbuch, p. 375-431, here in Gesammelte Abhandlungen, Berlin, Springer, 1968, vol. IV, p. 289-345.

WeYl (H.), 1949a, «Entwicklungslinien der Mathematik seit 1900. Problems and methods of $\mathrm{XX}^{\text {th }}$-century mathematics. Gastvorlesung nach 1950, englisch », Ms, Nachlass Weyl, Zurich, ETH Bibliothek, Hs 91a:72.

WeYl (H.), 1949b, Philosophy of mathematics and natural science, $1^{\text {st }}$ ed. Princeton, $2^{\text {nd }}$ ed. Princeton, NJ, Princeton University Press.

WeYl (H.), 1954, «Erkenntnis und Besinnung (Ein Lebensrückblick)», Studia Philosophica, here Gesammelte Abhandlungen, Berlin, Springer, 1968, vol. IV, p. 631-649.

WeYl (H.), 1968, Gesammelte Abhandlungen, ed. ChandraseKharan (Komaravolu), Berlin, Springer, 4 vol. 